\title{
The Italian Dental Sector in a Period of Economic Crisis
}

\author{
Elena Spina \\ Department of Economic and Social Sciences, Marche Polytechnic University, Italy
}

Copyright (C) 2015 by authors, all rights reserved. Authors agree that this article remains permanently open access under the terms of the Creative Commons Attribution License 4.0 International License

\begin{abstract}
A deep economic crisis started in Italy in 2008 leading to a reduction of general household consumptions, especially in the oral health care sector. The dental sector is characterized by the almost exclusively private nature of the services offered outside the INHS, thus taking the form of a demand-driven sector. The paper focuses on Italian dentists' perception of the economic crisis. It presents the first findings of an empirical research that was carried out in order to verify if and to what extent this occupational category perceived the economic crisis, if any threats were felt, what changes and challenges it was experiencing and what kind of strategies the profession has been implementing in order to overcome the crisis. Although dentists clearly state their problems and the perceived threats, they are not able to identify possible solutions as well.
\end{abstract}

Keywords Economic Crisis, Dental Profession, Dental Offer

\section{Introduction}

In 2008 a deep economic crisis, proved by a reduction in wealth in terms of gross domestic product $(-1.2 \%$ in 2008$)$ [1], began in Italy. Since then periods of stagnation have alternated with periods of recession. The explosion of the crisis was due to economic events that highlighted the strong contradictions of an already unbalanced and wobbly economic system [2,3]: even before 2008 the Italian economy was beset by structural problems that slowed down its growth and limited its ability to react adequately to external shocks (such as the international financial crisis). Several specific Italian factors worsened the economic recession, such as high levels of both tax evasion and public debt, a strong lack of infrastructures, evident differences in economic development between the north and south of the country and a lack of mid and long term policies capable of sustaining strategies for economic recovery and growth [4].

In terms of macroeconomic dynamics, this produced a dangerous spiral: the increase in unemployment [5] caused a reduction of household purchasing power and, as a result, a structural modification of these models of consumption occurred. Consumptions fell in all market sectors; what appears interesting, however, is the significant decrease in the health sector: in 2013, it was of 27,593 billion euro, while in 2012 and 2011 it was respectively of 29,245 and 29,557 (billion euro) [1]. In one year, the reduction was of $5.7 \%$ and reached $6.8 \%$ when adding the decrease of the previous two years.

Although the Italian National Health Service (IHNS) was established in 1978, some health services are not included in public coverage, such as dental treatments, which are provided only to marginal segments of the population. Consequently, dental services are mainly offered in the private market which thereby takes the form of a demand-driven sector. Being exposed to the economic conjuncture, this sector can suffer drastic contractions when economic crises occur, with deep effects on the supply as well as on the demand side. On the supply side, which includes dentists and all the satellite activities revolving around dental care [6], the reduction in consumption expenditure produces a decrease in incomes and, more broadly, in the general turnover. On the demand side, the reduction in consumptions, due to the forgoing of care, can have significant consequences in terms of oral health, exacerbating the already high social and health inequalities. Whereas this situation might be considered acceptable in a period of economic development and widespread prosperity, currently, 7 years since the onset of the crisis, the demand for a major public regulation of the dental sector as well as wider public coverage has increased. Even professional associations, who were reluctant to accept major government interventions, are now asking for a more direct engagement of the State in dental care due to the difficulties met in recent years.

The present paper focuses on Italian dentists' perception of the economic crisis. In this regard what should be noted is that this profession, compared to other health occupations, has been neglected by sociological studies [7] and for over 40 years "sociology has shown relatively little interest in exploring the mouth, or in engaging with dentistry: a sociology of the mouth remains absent" [8, p53].

In addition to the scant attention paid by the sociology of professions, there is insufficient available data on oral 
health and the access to oral services in Italy as well as in Europe. On the one hand, this is owing to the lack of reliable oral health monitoring systems in many countries; on the other, as suggested by Benzian et al. [9], it is due to international political neglect concerning oral health issues. According to the authors, this neglect is documented by a number of factors such as the exclusion of oral health from the framework of most Primary Health Care systems, the disinterest in the analysis of health policies for oral health and the lack of attention to the latter in the context of emerging patterns of social health insurance.

Because of its peculiar characteristics, dentistry appears, instead, to be a particularly interesting field of study, first of all from a sociological point of view.

For this reason, the Interdepartmental Centre for the Research and Services on Social and Health Integration (CRISS) of the Università Politecnica delle Marche has formed a collaborative relationship with the Provincial Order of Physicians and Dentists of Ancona in order to carry out research on the dental profession, on its historical evolution and on the configuration of oral health in Italy.

Some preliminary findings, focusing on the current situation, will be presented in the following sections of this article.

\section{The Dental Supply in Italy: A Snapshot}

At the end of 2014 the number or dentists enrolled with the register kept by the National Federation of the Orders of Physicians and Dentists (FNOMCeO) was 59,372, showing a significant increase compared to previous years $(+5 \%$ since $2010,+28 \%$ since $2005,+79 \%$ since 2000 ) [10].

As a result, in Italy there is currently 1 dentist per 1,019 inhabitants, a considerably high ratio, which is well above the standard recommended by the World Health Organization (1 per 2000 inhabitants) and the European average (0.6 dentists per 1000 inhabitants, EU-27, 2009).

As regards distribution by age, the largest cohort is the one which includes professionals between 55 and 64 years of age, followed by the cohort including dentists between 45 and 54 years of age; the under- 45 cohort represents $27.9 \%$ of the total and the over-65 cohort $7.1 \%$ [10]. Compared to previous studies, recent data show how the most significant increase can be seen in the over-55 cohort while the remaining cohorts show a decrease, thus confirming a trend of stabilization in the number of dentists.

As concerns gender composition, women represent $24.1 \%$ of the total number of dentists enrolled with the Order (13,821 vs. 43,556 men), although their distribution by age shows a growth. This suggests that the dental sector has started to interest women only in recent years: the over-59 group comprises 969 women, just $8.9 \%$ of all those enrolled, but the percentage rises to $46 \%$ in the $24-34$ years of age bracket and $40 \%$ in the 35-39 year old cohort [10]. At a European level, the situation is quite different: data produced by ERO teamwork [11] show that the female percentage is about $60 \%$. Whereas in western Europe (apart from Sweden and Finland) the dental profession is practised mainly by men, in the rest of the European Union women are the majority, reaching peaks in Estonia, Lithuania and Poland where the percentages are over $80 \%$.

Inspection of the geographical distribution shows a significant heterogeneity, which contributes to the fragmentation of the Italian supply: the northern regions have the highest number of dentists $(49.27 \%)$, followed by the central regions $(21.84 \%)$ and by the southern ones $(21.45 \%)$; the islands close the ranking, with $9.42 \%$ of dentists [12]. According to data provided by the National Association of Italian Dentists [13] the regions with the greatest concentration of dentists are Liguria (with 1 dentist per 767 inhabitants), Friuli Venezia Giulia (1:803), and Marche (1:851); Valle d'Aosta $(1: 1,623)$ and Basilicata $(1: 1,406)$ close the ranking.

A similar heterogeneity is observed between metropolitan areas, crowded with professionals, and suburban ones, where the supply is weaker, testifying to a complete lack of planning with respect to the location choices of professional clinics [14].

The dental sector is currently characterized by the almost exclusively private nature of the services offered outside the INHS. This is not an anomaly in Europe, where oral healthcare is mostly provided by private dental practitioners [15]. Italy, however, is at the bottom of the ranking: data of the Ministry of Health (2011) for the year 2010 show that the INHS performs only 0.6 visits per year per citizen compared to 1.8 visits in Belgium, 1.4 in Germany and 2.1 in the Netherlands [16]. As above mentioned, the INHS provides free dental care only to marginal segments of the population (people in vulnerable conditions) as well as to children under 14 years of age. However, these services are provided differently in each regional health service following the 1992-1993 health reform, which triggered a process of health regionalisation, and the 2001 Constitutional Reform, which continued the process of health de-centralisation [17]. Since there are no recent data on the number of dentists working in the INHS, we must rely on the data published in a 2006 study. According to this source, 3,457 dentists work in the public sector $(6.5 \%$ of the total); 1,094 dentists are INHS employees, 249 dentists have fixed-term contracts, and 2,114 dentists have INHS contracts [18]. Recent estimates [13] show that the number of dentists working in the public sector has risen to approximately 4,000 , representing $8 \%$ of all enrolled professionals who, however, meet less than $10 \%$ of the demand [19].

As concerns the organization of work, the prevailing organizational model is based on small or medium sized individual clinics where the professional works autonomously, sometimes assisted by collaborators.

There are approximately 40,000 private dental clinics in Italy, with $71.9 \%$ of them run by sole practitioners and $11.5 \%$ through partnerships. This confirms the prevalence 
of the "solo practice" model throughout the country [19]. According to the ANDI [13], innovation processes, whereby dentists group together to create larger practices, do exist; however, this phenomenon has nothing to do with joint stock companies, which are a minority $(2.5 \%)$. The typical dental clinic has a surface area of about $100 \mathrm{~m} 2$, is equipped with two dental treatment chairs, and has 2 employees and 1.5 assistants. The number of employed staff is also low because Italian dentists tend to perform tasks that abroad are usually delegated to others. For example, $80.3 \%$ of them perform oral hygiene personally, without resorting to a specific professional figure [13]. The use of traditional technology has been stable over time, but a growing number of dentists possess the most advanced instruments and technology available on the market.

\section{The Other Half of the Sky: The Demand for Dental Care}

The increase in the supply of dentists does not appear to reflect the increase in demand which, on the contrary, is recording a gradual reduction $[6,20]$. According to periodic surveys carried out by Key-Stone, in 2011 a further decline in the number of patients (3\%) was recorded; it resulted in an overall reduction in the number of users of about 3 million since 2009 [21]. This decrease does not appear due to a general improvement in dental health as the need for care still seems rather high in Italy. Data of the ANDI [14] show that, although over the last 30 years the Italian trend has been positive (the value of the decayed-missing-filled teeth index decreased from 5.5 teeth in 1980 to 2.1 teeth in 2000), the need for care remains among the highest in industrialized countries.

The economic crisis has certainly contributed to the contraction of the demand: the fall of disposable income, owing to an increase of both fiscal pressure and inflation, has drastically reduced household consumptions [1]. Therefore, families are reducing the quantity and quality of goods and services and are implementing strategies to cut spending in all sectors [1], including the health sector. Consequently, a drop in access to dental services has been observed [6] since they are perceived as not urgent and extremely expensive. Moreover, currently in Italy dental expense is borne by users (85.7\%) [1]; even in the case of pediatric dentistry, $82.3 \%$ of people choose the private sector, despite the existence of preventative oral health programs for minors.

Although dental treatment is the most frequent specialist treatment in general $(16.4 \%)$, there has been a significant reduction $(-23.1 \%)$ since 2005 . This decrease concerns all types of dental treatment: check-ups and oral hygiene (from $75.8 \%$ to $64.9 \%$ ), dental extractions (from $19.9 \%$ to $12.9 \%$ ) and fillings (from $43.5 \%$ to $25.5 \%$ ). What has increased is the number of prostheses, bridges and implants (from $12.3 \%$ to $16.5 \%$ ) and this seems to follow the evolution of dental treatment. In fact, aesthetic dentistry (such as whitening) shows a strong growth (from $1.1 \%$ to $6 \%$ ) $[1,22]$.

In particular, according to recent Istat data [22], in 2013 the number of people who went to a dentist or an orthodontist in the 12 months preceding the interview was more than 22 million, representing $37.9 \%$ of the population over 3 years of age $(39.3 \%$ in 2005). The National Guidelines for the promotion of oral health and the prevention of oral diseases [23], recommend at least one dental check up a year. The delay of care is a critical issue because of the economic situation.

The general decline in dental care, compared to 2005, is mainly due to fewer visits to private dentists: the share of the population resorting to a private dentist was $32.3 \%$ (34.7\% in 2005). Instead, the use of public dental clinics appears to be stable over time (5.4\%). Moreover, those who went to a dentist underwent fewer procedures than in 2005: the number of those who had only one type of treatment increased (from $49.3 \%$ to $70.7 \%$ ), while those who combined more than one treatment fell [22]. As concerns dental reconstruction, aimed at preserving natural teeth (fillings, root canal, etc.) the share of people dropped by half (from $17.1 \%$ to $9.6 \%$ ). The number of people who have completely replaced missing teeth with a prosthesis or a complete implant, also decreased, especially among older people (from $76.2 \%$ to $67 \%$ for over 65 year olds) [22].

In addition, $14.1 \%$ of people over the age of 14 forwent care or dental treatment in 2013 , in $85.2 \%$ of cases for economic reasons [22].

The very high level of social inequality is evident in Italy in both access to dental care and levels of dental health. In this regard what is seen at an international level is confirmed in this country: poorer oral health and less frequent access to preventative oral healthcare are more prevalent amongst deprived groups [25,26]; they are particularly marked amongst pre-school children from less affluent socioeconomic groups [27]; there are also regional inequalities in oral health [28] and evident generational differences [29-31].

Social inequalities in health and oral prevention as well as in access to care appear to be marked and more pronounced than in 2005, to the detriment of people who are poorly educated and with limited economic resources[22]. In this regard, several studies show that people with low income or with a low level of education, ethnic minorities or people with the very weak networks of social capital, experience greater difficulty in access and in the use of dental services, despite actually having the greatest need [32-36]. In Italy this correlation is confirmed by the fact that in 200t7 the DMFT index had an inversely proportional value to the gross national product per capita [37].

Italy is the country, in Europe, with the highest percentage of people who forgo oral treatment for economic reasons, showing the highest differential between 2011 and 
2007 ( $\Delta 3.1 \%)$. This negative record can only be understood in the light of the economic crisis that hit Italy [38].

Good economic conditions can both facilitate the access to preventive dental treatments and reduce the forgoing of dental care: $23.7 \%$ of people with scarce or insufficient resources had to forgo dental care compared to $7.9 \%$ of those with excellent or adequate resources. In general, however, economic factors are the main reason of forgoing even among those who report excellent or adequate family resources. Strong inequalities also emerge territorially: in the south of Italy forgoing is higher, and more often due to economic reasons $(14.5 \%)$, than in the north $(10.6 \%)$ and centre of the country $(10.9 \%)$ [22].

As well as increasing inequalities, the forgoing of care, which is exacerbated by the economic crisis, has definite repercussions on the level of oral health as well as on the general health of the population. The entity of this impact in the short and long period remains to be seen.

\section{An Empirical Research: Aims and Methods}

Is it possible to hypothesize that the reduction in the number of patients is not due solely to the economic crisis and to the decrease in disposable income? Is it because of other reasons as well, including the professional behaviour of dentists and their prevailing organizational model based on the relationship of trust with the patient rather than on a managerial model? In other words, is it possible that the lack of entrepreneurial ability among dentists makes the market demand-driven by limiting its expandability as well as its growth potential?

In order to answer these questions CRISS launched an empirical research in Italy in 2013. The aim was to understand the prevalent orientation of the Italian dental profession in order to verify if and to what extent this occupational category perceived the economic crisis, if any threats were felt, what changes and challenges it was experiencing due to the crisis and what kind of strategies the profession has been carrying out in order to overcome it.

The research was performed using quali-quantitative methods.

Firstly, a focus-group was organized with the 5 presidents of the provincial Order of Physicians and Dentists of Marche region. The focus-group was useful to gain a clearer and more detailed picture of the professional situation, to find out what issues were at the heart of the debate and to refine methodological tools to be used in the further stages of the research. On the basis of suggestions made by participants, the research team created a semi-structured questionnaire, consisting of 17 questions focused on the perception of the economic crisis. After validating the questionnaire, thanks to the collaboration of the president of the Provincial Order of Ancona, it was distributed during a national meeting held in Rome in May
2013; 66 of the 105 provincial presidents answered the questionnaire, yielding a response rate of $63 \%$. This response rate allowed us to consider the results as representative of the orientation as perceived by the heads of the professional association in Italy.

\section{The Economic Crisis: Dentists' Perceptions}

Although the dental sector has felt the economic crisis widely, only $14 \%$ of the respondents state that their own clinic has been affected by the recession. When referring to the professionals they represent, however, over $90 \%$ of them confirm the trend towards a strong decline in the number of patients since 2008. The most affected sector is prosthetics $(57.3 \%)$, followed by prevention $(16.4 \%)$ and basic care $(13.1 \%)$. On the one hand, the collapse of the prosthetic industry is related to the high cost of dental implants; on the other, the resilience of emergency treatments is connected to the reduction in prevention that, consequently, has resulted in an increase of oral diseases.

According to the respondents, there are many reasons for the decrease in the number of patients leading to a reduction of the income guaranteed by professional practice (95.3\%).

The main reason is the economic crisis $(95 \%)$, that has reduced household purchasing power. In addition, patients have different behaviours to those of the past: they appear to be more demanding $(89 \%)$ and also more knowledgeable, sometimes acquiring information of poor quality (79.7\%). This has led dentists to change the way in which they practice as a necessary consequence.

Another reason linked to the decline in demand is increased competition (96.8\%), which is related to different causes. First of all, the oversupply of graduates (51.8\%) due to:

a. the excessive number of students enrolled with Italian universities. However, a steady downward trend of graduates, who dropped from 1,537 units in 2005 to 993 in 2010, has been observed recently[39]. Compared with data on the age distribution of dentists, this trend should lead to a relative stabilization in the number of professionals, considering that many of those who are currently practicing will exit the labour market in the near future [16].

b. the increase in the number of Italian students who attend foreign universities (where the lack of admission tests facilitates access) and then return to Italy to practice dentistry. The most popular destination is Romania; according to recent_data, over the last 5 years about 5,000 Italian students have chosen private universities in Romania [40] and in 2008,82 recognitions for the practice of dentistry were authorized by the Ministry of Health [39].

Dental tourism is also perceived as a problem $(60 \%)$. This is not a recent phenomenon: the outflow of patients 
began in the 1970s, mainly towards the Netherlands, where it was possible to receive prosthetic treatment in a few days. Since then, the phenomenon has increased, and several satellite activities have sprung up around it, so much so that in recent years specialized tour operators have begun to organize "tooth journeys". Currently, however, dental tourism seems to be decreasing due to the closer attention paid by patients to the quality of services and the safety of treatments [41]. The survey carried out by ANDI in 2013 [13] confirms the decline of this trend, showing that only $4 \%$ of Italians have chosen to go abroad for dental treatment at least once (half of them stated, however, that they regretted doing so) and that only $15 \%$ were willing to consider this option.

Just under a third of respondents blame the reduction in the number of patients on the difficulty of dentists to promptly respond to the recessive situation.

The increasing number of low-cost clinics is also a critical factor as it determines a growth in competition. This phenomenon consists in the increasing penetration of the domestic market by multinational franchises which provide low-cost dental treatment, resulting in a sharp increase in competition [42]. This represents a threat for just under half of the respondents but the percentage rises to $90 \%$ when adding those who only partly consider it as a danger.

Finally, unfair competition comes from illegal practice (72.1\%). This is still punished with derisory penalties even though it is seriously compromising the social credibility of the profession and creating distrust among the population.

The increased managerial costs of clinics $(81.8 \%)$ as well as national legislation, which is perceived as excessively binding and penalizing, are considered further insidious threats for the dental profession, especially in a period of crisis.

Therefore, the dental sector is currently facing multiple and diverse critical issues. These difficulties are exacerbated by the partial isolation in which the profession seems to be because of a strong crisis of representation that is evident at all levels: political, that of the trade unions and professional.

As regards the political level, the crisis of representation appears to be total since disapproval, which translates into distrust in political institutions, reaches its peak: $100 \%$ of respondents accuse the latter of inertia.

At the level of trade union representation also, a negative assessment tends to prevail considering that more than $60 \%$ of dentists believe that these bodies are not doing enough to protect the sector. However, the most interesting data undoubtedly concerns the professional level: more than $60 \%$ of dentists accuse the Professional Order of not taking appropriate and effective measures to combat the economic crisis. A widespread distrust towards the professional representation body emerges and what is striking is that this distrust is shown by the representatives of the profession.

The picture that emerges shows a general distrust in institutions from which the profession should be protected.
At the same time, it demands an implementation of institutional commitment in order to overcome the economic crisis. In particular, institutions should fight illegal practice, support young professionals and also promote information campaigns aimed both at protecting users and at re-launching the social visibility of the dental profession. The latter aspect, in particular, seems to be felt strongly by the profession which claims to be the victim of a smear campaign by the media resulting in widespread distrust among the population. This may have prompted the profession to adopt defensive practices: in dentistry, in fact, an excessive use of such practices could spread further, with a significant economic impact and mainly to the detriment of patients.

\section{Overcoming the Problems: Some Suggestions}

Although dentists clearly state their problems and the perceived threats, they are not able to identify possible solutions as easily. What is evident to them, however, is that "one best way", which can overcome the economic crisis as well as re-launch the dental sector, does not exist. Less than $1 / 3$ of the respondents claim that it will be necessary to re-qualify the professional services offered by clinics through the improvement of performance, the investment in technological equipment, the changing of organizational structures and a commitment to a continuous updating of knowledge.

The identification of an organizational solution also appears to be strongly appreciated by respondents who feel it is important to promote associative practices $(17.5 \%)$ as well as agreements among colleagues $(5 \%)$ in order to exploit economies of scale.

About 1/5 of the respondents agree with solutions based on training tools: in their opinion it is necessary to increase investments in training activities (11.3\%) as well as to promote a better specialization of competences and skills (7\%) so as to offer a more comprehensive and diversified portfolio of services.

Only $11.3 \%$ of dentists identify a possible way out of the crisis in the request for support from institutions. The latter should promote informative campaigns in order to reassure users by offering them the chance to consult the professional register. Political institutions, in particular, should revise some of the rules that currently govern the dental profession, such as those concerning advertising and the minimum fee.

Finally, investments in technology do not represent a credible solution to the economic crisis, considering that only $10 \%$ of respondents have chosen this option. This suggests that dentists' technological equipment is up-to-date and, therefore, that Italian dental clinics have never reduced their technological investment even in difficult economic periods [43]. 
To sum up, the solutions preferred by respondents appear to be rather heterogeneous and do not draw a clear path to overcome the crisis. In fact, they seem to be based on a combination of tools: the organizational one, which requires a revision of the prevailing model based on individual clinics, in favour of a business model based on associated clinics with an entrepreneurial approach; the training tool, which enhances dentists' professionalism through a constant updating of skills; the technological tool, offering adequate responses to the demand for care expressed by users.

Efforts of cooperation with institutions should be added also since they are conducive, on one hand, to protecting users and supporting them so that they do forgo care and, on the other, to supporting the professional activities of Italian dentists, thus contributing to revitalize the sector.

\section{What about the Future? Some Considerations}

The data presented in the previous sections offer a fairly clear indication of the current situation of the dental sector in Italy.

On the demand side, a reduction in access to oral care emerges: according to Istat data $[1,23]$ dental treatment is the health service that people forgo most frequently and the this is mainly due to economic problems. This forgoing care produces obvious consequences in terms of oral health, and overall health. What seems interesting to understand is what the impact will be in the short and long period.

In this regard, the literature provides two different interpretations.

On one hand, some studies, which are not specifically focused on oral health, have shown a positive correlation at the individual level among low income, unemployment and poor health [44-48]. The idea that the financial crisis could harm health also reflects the findings of the Commission on Social Determinants of Health published in 2008 [49]. A large body of research has documented the detrimental effects of unemployment on health at the level of individual resources. Limited financial resources can lead to poor nutrition and to a restriction in access to health care when needed. A lower socioeconomic status is associated with poorer physical health [50-53], a lower degree of emotional and psychological health [54,55], and an increased risk of mortality [56-58].

On the other hand, several researchers argue the opposite: a recession might actually improve health, at least in the short run. Authors using aggregate time series data [59-65] show that negative deviations from the long term per capita GDP trend are closely associated with reductions in a wide range of cause-specific mortality rates. So-defined "recessions" would accordingly seem to be 'good' for overall health, at least in the short term. Ruhm and others, for example, claim that during recessions the level of health improves as individuals favourably change their dietary habits as well as reducing detrimental lifestyle habits [60].
Clearly, more research is needed to understand the health equity implications of recessions (and economic upturns). Some variables should be further assessed, first of all those related to the wealth of each country, the level of coverage of public services and the existence of inequalities.

In this regard, some studies focus on the relation between welfare regimes and oral health. Using both the distinction among different welfare regimes suggested by Ferrera [66] and Eurobarometer data [67], Sanders et al. [68] and Guarnizo-Herreño et al. [69], for example, state that "a welfare regime with more redistributive and universal welfare policies results in better general oral health" and that this achievement, which has been reached in Scandinavian countries "could also be related to their health policies. They explicitly target the social determinants of health $[\ldots]$ and have a large number of universal health-care services with a high level of decommodification" [69,p.172]. Therefore, the authors conclude that "the mechanisms linking general health and broad social determinants are also relevant to oral health".

On the above mentioned issue, a debate on the non-inclusion of oral health in National and community health programmes aimed to protect public health is beginning [70-72]. However, this aim seems to clash with the general trend towards a more market-oriented solution to the problem of allocating healthcare resources, as adopted in many countries [32]. Instead, it should be pursued by seeking the cooperation of all the actors involved in governance (public institutions, educational systems, citizen-users, etc.). A major role should be played by professionals who must carry out structural change in the organization of care. Fejerskov et al. [73], referring to the US context, focus on two aspects in particular. On the one hand, starting from the consideration that the dentist remains "a technically skilled precision mechanic, able to provide highly complex restorative care, but often with limited insight into the underlying biological, cultural and social issues related to the patient's and population's oral health care" [73, p716], the authors call for a change in academic curricula; on the other, they state the need for greater integration among health professionals. Finally, they argue that "the ideal oral healthcare system cannot be achieved through minor adjustments of the dental curriculum, or of the number of dental specialties, the payment systems or the solo practice-based delivery system. In our view, it necessitates a more profound break with long-standing traditional thinking in dental education and in oral healthcare delivery organisation" [73, p717].

On the supply side, the empirical findings convey the idea of a professional category that, perhaps for the first time, is experiencing a very difficult period. Critical issues arise on many fronts and cannot be attributed solely to the economic downturn that began in 2008. Certainly, the recession has exacerbated existing problems: the decreased number of users of professional clinics has reduced profits.

The problems, however, appear to be structural. On the one hand, problems of self-regulation emerge and are 
particularly evident in the failure to counter illegal practice; on the other, there is an organizational inability, demonstrated by the fragmentation of the supply and the prevalence of an organizational model that is unable to exploit economies of scale.

In terms of public regulation, what should be noted is that deficient and ambiguous public attempts to regulate the sector represent an element of continuity in the history of Italian dentistry [19]. The incomplete nature of public regulation granted the profession wide margins of freedom and autonomy, which also favoured the implementation of opportunistic behaviour and, ultimately, the development of an illicit market. However, it was the lack of a specific professional Order that, in turn, may have hindered the emergence and the development of a spirit of belonging. The difficulty felt by dentists in identifying with a representative body, which was established to represent doctors, may have actually limited the development of a corporative spirit, already partly compromised by the fragmentation of the professional group, composed of a large number of small individual clinics. Subsequently, this could have weakened the possibility to practice the voice option [74], thus compromising the ability of dentists to lobby with policy makers and penalizing their social visibility.

Italian dentistry should act on all these fronts in order to re-launch the sector; looking to the economic crisis as an opportunity to renovate an organizational model that appears to be unsustainable in the long period. It should regain public legitimation through both a tighter control of the illegal market and the stipulation of a new contract with users. The latter have, in fact, deeply changed compared to the past, displaying different problems, experiencing growing difficulties and inequalities in access to care.

\section{REFERENCES}

[1] Istituto Nazionale di Statistica. Rapporto annuale 2013. La situazione del paese, ISTAT, Roma, 2013.

[2] G. Fattore, G. Mariotti, V. Rebba. Chapter 9: Italy. In Siciliani L, Borowitz M, Moran V. Waiting Time Policies in the Health Sector: What Works. OECD Health Policies Studies. OECD publishing, 2013.

[3] A.G. De Belvis, F. Ferrè, M.L. Specchia, V. Luca, G. Fattore, W. Ricciardi.The Financial Crisis in Italy: Implication for the Healthcare Sector, in Health Policy, 106, 11, 10-16, 2012.

[4] P. Mladovsky, D. Srivastava, J. Cylus, M. Karanikolos, T. Evetovits, S. Thomson, M. McKee. Health policy responses to the financial crisis in Europe. Policy summary 5. World Health Organization on behalf of the European Observatory on Health Systems and Policies, Copenhagen, 2012.

[5] Istituto Nazionale di Statistica. Rapporto annuale 2015. La situazione del paese, ISTAT, Roma, 2015.
[6] Key-Stone. Neppure il sorriso accompagna il pesante anno degli italiani: un milione in meno dal dentista, un settore per la prima volta in recessione, 2010 http://www.key-stone.it/immagini/researc_edu/Ricerca_crisi _dentale.pdf

[7] Exley C. Bridging a gap: the (lack of a) sociology of oral health and healthcare, Sociology of Health \& Illness, 31(7), 1093-1108, 2009.

[8] Graham, R. Lacking compassion - sociological analyses of the medical profession. Social Theory \& Health, 4, 43-63, 2006.

[9] H. Benzian, M. Hobdell, C. Holmgren, R. Yee, B. Monse, J.T. Barnard, H.W. van Palenstein. Political priority of global oral health: an analysis of reasons for international neglect, International Dental Journal, 61(3), 124-130, 2011.

[10] Federazione Nazionale degli Ordini dei Medici Chirurghi e degli Odontoiatri, Medici e odontoiatri iscritti all'Ordine a Gennaio 2015, Centro Studi, Roma, 2015.

[11] ERO (ed), Women in dentistry. Report 2012, available at www.erodental.org.

[12] Federazione Nazionale degli Ordini dei Medici Chirurghi e degli Odontoiatri, Medici e odontoiatri iscritti all'Ordine ad Aprile 2012, Centro Studi, Roma, 2012.

[13] National Association of Italian Dentists (ANDI), Rapporto. 61 congresso scientifico nazionale ANDI. Roma, 15-16 Novembre 2013.

[14] National Association of Italian Dentists (ANDI), la crisi del settore dentale in Italia: analisi e misure di rilancio, 2005, available at

http://www.cna.it/SNO/DOCUMENTI/COMPARTO-DELDENTALE

[15] V. Paris, M. Devaux, L. Wei, Health Systems Institutional Characteristics: A Survey of 29 OECD Countries. OECD Health Working Papers, OECD Publishing, Paris, 2010, available at http://dx.doi.org/10.1787/5kmfxfq9qbnr-en.

[16] A. Gugiatti, F. Longo, L'assistenza odontoiatrica in Italia: analisi del settore e possibili traiettorie di evoluzione, Mecosan, n. 69, 113-127, 2009.

[17] E. Pavolini, G. Vicarelli, Is decentralization good for your health? Transformations in the Italian NHS, Current Sociology, 60(4), 472-488, 2012.

[18] Ministry of Health, Odontoiatria di comunità: criteri di appropriatezza clinica, tecnologica e strutturale, Quaderni del Ministero della Salute, 7, 1-244, 2011.

[19] G. Vicarelli, E. Spina, Professionalization and Professionalism: The Case of Italian Dentistry, Profession \& Professionalism, Vol. 5, n. 3, 2015.

[20] R. Rosso, Dentisti sell out a studio $-6 \%$. Calo strutturale del business, Il Sole24Ore Sanità, 21-27 maggio 2013, 12-13, 2013.

[21] R. Rosso, Tre milioni di pazienti lasciano gli studi, Il Sole24Ore Sanità», 22-28 maggio 2012, 14-15, 2012.

[22] Istituto Nazionale di Statistica, I consumi delle famiglie. Anno 2004, ISTAT, Roma, 2005. 
[23] Istituto Nazionale di Statistica, Il ricorso alle cure odontoiatriche e la salute dei denti in Italia. Anno 2013, ISTAT, Roma, 2015.

[24] Ministry of Health, Linee guida nazionali per la promozione della salute orale e la prevenzione delle patologie orali in età evolutiva, Ministero della salute, 2013, available at: http://www.salute.gov.it/imgs/c_17_pubblicazioni_2073_alle gato.pdf

[25] M. Kelly, J. Steele, N. Nuttall, G. Bradnock, J. Morriss, J. Nunn, C. Pine, N. Pitts, E. Treasure, D. White, Adult Dental Health Survey: Oral Health in the United Kingdom in1998, The Stationery Office, London, 2000.

[26] P.E. Petersen, T. Yamamoto, Improving the oral health of older people: the approach of the WHO Global Oral health Programme, Community Dentistry and Oral Epidemiology 33, 81-92, 2005.

[27] K. Hinds, J.R. Gregory, National Diet and Nutrition Survey: Children Aged $1 \frac{1}{2}$ to $4 \frac{1}{2}$ Years. Volume 2: Report of the Dental Survey, HMSO, London, 1995.

[28] R. Watt, A. Shaeiham, Inequalities in oral health: a review of the evidence and recommendations for action, British Dental Journal, 187, 6-12, 1999.

[29] J. Nunn, J. Morris, C. Pine, N. Pitts, G. Bradnock, J. Steele, The condition of teeth in the UK in 1998 and implications for the future, British Dental Journal , 189, 639-44, 2000.

[30] J.G. Steele, E. Treasure, N. Pitts, J. Morris, G. Bradnock, Total tooth loss in the United Kingdom in 1998 and implications for the future, British Dental Journal, 189, 598$603,2000$.

[31] B. Gibson, Access to dental services. In M. Gulliford, and M. Morgan (eds), Access to Health Care, Routledge, London, 2003.

[32] J.L. Leake, S. Birch, Public policy and the market for dental services, Community Dentistry and Oral Epidemiology, 36, 287-295, 2008

[33] H.P. Lawrence, W.M. Thomson, G.M. Broadbent, R. Poulvac, Oral health-related quality of life in a birth cohort of 32-years old, Community Dentistry and Oral Epidemiology, 36 (4), 305-316, 2008.

[34] R. Patel, The State of Oral Health in Europe, Report Commissioned by the Platform for Better Oral Health in Europe, 2012, available at: https://www.mah.se/PageFiles/49503/Report\%20-\%20the\%2 0State $\% 20$ of $\% 20$ Oral\%20Health\%20in\%20Europe.pdf

[35] J.Y. Lee, K. Divaris, The Eth Hical imperative of Addressing Oral Health Disparities: A Unifying Framework, Journal of Dental Research, XX(X), 1-7, 2013.

[36] L. Palencia, A. Espelt, M. Cornejo-Ovalle, C. Borrell, Socioeconomic inequalities in the use of dental care services in Europe: what is the role of public coverage? Community Dentistry and Oral Epidemiology, 42, 97-105, 2014.

[37] G. Campus, G. Solinas, M.G. Cagetti, A. Senna, L. Minelli, S. Majori, M.T. Mountain, D. Royal, P. Castile, L. Strohmenger, National Pathfinder survey of 12-year-old Children's Oral Health in Italy, Caries Research, 41, 512-517, 2007.
[38] Eurostat, EU Statistics on Income and Living Conditions, 2013

[39] N. Maccagno, La mobilità dei professionisti: uno sguardo all'Europa, 2010, available at http://www.odontoconsult.it/cont/pubblica/attualita/contenuti /884/mobilita-professionisti-sguardo-alleuropa.asp

[40] M. Focarete, Nell' ateneo romeno che trasforma le matricole italiane in dentisti, Corriere della sera, 10 aprile 2012, p. 26, 2012.

[41] F. Bambara, Turismo odontoiatrico. Il problema sta a monte, Senzaetà, 56, 26-27, 2013.

[42] D. Di Vico, Le ansie dei dentisti: i prezzi scenderanno e la qualità rischierà. Priorità investire, Corriere della Sera, 23 gennaio 2012, p. 7, 2012.

[43] N. Maccagno, Monoprofessionali ma hi-tech. Ancora poco diffuse le società. La richiesta: «Più detrazioni per i pazienti», Il Sole24Ore Sanità, 21-27 maggio 2013, p. 14, 2013.

[44] R. Catalano, B. Bellows, If economic expansion threatens public health, should epidemiologists recommend recession? International Journal of Epidemiology, 34(6), 1212- 213, 2005.

[45] A.E. Clark, A.J. Oswald, Unhappiness and unemployment, Economic Journal, 104 (424), 648-659, 1994.

[46] F. McKee-Ryan, Z.L. Song, C.R. Wanberg, Psychological and physical well-being during unemployment: a meta-Analytic study, Journal of Applied Psychology, 90(1), 53-76, 2005.

[47] G. C. Murphy, J.A. Athanasou, The effect of unemployment on mental health, Journal of Occupational and Organizational Psychology, 72, 83-99, 1999.

[48] W.T. Gallo, E.H. Bradley, J. Dublin, Involuntary job loss as a risk factor for subsequent myocardial infarction and stroke: findings from the health and retirement survey, American Journal of Industrial Medicine, 45(5), 408-416, 2004.

[49] M. Marmot, S. Friel, R. Bell, Closing the gap in a generation: health equity through action on the social determinants of health, Lancet, 372 (9650),1661-1669, 2008.

[50] T.A. Blakely, K. Lochner, I. Kawachi, Metropolitan area income inequality and self-rated health - a multi-level study, Social Science \& Medicine, 54 (1), 65-77, 2002.

[51] R. Ecob, G.D. Smith, Income and health: what is the nature of the relationship? Social Science \& Medicine, 48(5), 693-705, 1999.

[52] E. Grundy, G. Holt, Adult life experiences and health in early old age in Great Britain, Social Science \& Medicine, 51 (7), 1061-1074, 2000-

[53] A. Wagstaff, P. Paci, H. Joshi, Causes of inequality in Health: Who are you? Where you live? Or who your parents were? The World Bank, Washington DC. Policy research Working Paper No 2713, 2001

[54] S.A. Everson, S.C. Maty, J.W. Lynch, Epidemiologic evidence for the relation between socioeconomic status and depression, obesity, and diabetes, Journal of Psychosomatic Research, 53 (4), 891-895, 2002.

[55] I. Theodossiou, The effects of low-pay and unemployment on psychological well-being: a logistic regression approach, 
Journal of Health Economics, 17 (1), 85-104, 1998.

[56] J. Gardner, A.J. Oswald, How is mortality affected by money, marriage and stress? Journal of Health Economics, 23 (6), 1181-1207, 2004.

[57] N. Goldman, S. Korenman, R. Weinstein, Marital status and health among the elderly, Social Science \& Medicine, 40 (12), 1717-1730, 1995.

[58] C.T.M. Van Rossum, H. Van de Mheen, J.P. Mackenbach, Socioeconomic status and mortality in Dutch elderly people - The Rotterdam study, European Journal of Public Health, 10 (4), 255-26, 2000.

[59] U. Gerdtham, M. Johannesson, Business cycles and mortality: results from Swedish microdata, Social Science \& Medicine, 60 (1), 205-218, 2005.

[60] C. Ruhm, Are recessions good for your health? Quarterly Journal of Economics, 115 (2), 617-650, 2000.

[61] C. Ruhm, Good times make you sick, Journal of Health Economics, 22 (4), 637-658, 2003.

[62] C. Ruhm, Macroeconomic conditions, health and mortality, in A. Jones (Ed.), Elgar companion to health economics, Edward Elgar Publishing, Cheltenham, UK, 2006.

[63] C. Ruhm, Macroeconomic conditions, health and government policy, in R. Schoeni, J. House, G. Kaplan, \& H. Pollack (Eds.), Making Americans healthier: Social and economic policy as health policy, Russell Sage, New York, 2008.

[64] J.A. Tapia Granados, Recessions and mortality in Spain, 1980-1997, European Journal of Population, 21, 393-422, 2005.
[65] J.A. Tapia Granados, Macroeconomic fluctuations and mortality in postwar Japan, Demography, 45, 323-343, 2008.

[66] M. Ferrera, Le politiche sociali, Il Mulino, Bologna, 2006.

[67] European Commission. Eurobarometer 72.3: Public Health Attitudes, Behavior, and Prevention, October 2009.

[68] A.E. Sanders, G.D. Slade, M.T. John, J.G. Steele, A.L. Suominen-Taipale, S. Lahti, N.M. Nuttall, P.F. Allen, A cross-national comparison of income gradients in oral health quality of life in four welfare states: application of the Korpi and Palme typology. Journal of Epidemiology and Community Health, Jul;63(7), 569-74, 2009.

[69] C.C. Guarnizo-Herreño, G. Tsakos, A. Sheiham, R.G. Watt, Oral health and welfare state regimes: a cross-national analysis of European countries, European Journal of Oral Sciences; 121: 169-175, 2013.

[70] P.E. Petersen, Strengthening of Oral Health Systems: Oral Health through Primary Health Care, Medical Principles and Practice, 23(suppl 1), 3-9, 2014.

[71] E. Honkala, Primary Oral Health Care, Medical Principles and Practice, 23, 17-23, 2014.

[72] S. Tomar, L. Cohen, Developing a new paradigm for the dental delivery system. Journal of Public Health Dentistry, 70(Special Issue), S6-S14, 2010.

[73] O. Fejerskov, G. Escobar, M. Jossing, V. Baelum, A functional natural dentition for all-and for life? The oral healthcare system needs revision. Journal of Oral Rehabilitation, 40, 707-722, 2013.

[74] A.O. Hirschman, Exit, Voice, and Loyalty: Responses to Decline in Firms, Organizations, and States, MA: Harvard University Press, Cambridge, 1970. 